\title{
The convergence of man and woman gender in Xinjiang national diet folk
}

\author{
Zhang Chun-ping \\ Shangqiu medical college,Shangqiu Henan, 476000,china
}

\begin{abstract}
The general idea is that woman is the main part of the diet activities from the traditional society to the modern civilized society, but the difference between woman and man is more obvious in specific diet etiquette. The reasons for the gender differences not only are related to the nature of the woman, but also are connected to the age and society. It is encouraging that the improvement of social civilization and the consciousness of equality between man and woman have been gradually formed with the progress of the times, the Xinjiang national diet custom differences between man and woman are diminishing.
\end{abstract}

Key words- Xinjiang diet custom; Gender differences; The convergence

\section{INTRODUCTION}

As the saying goes, food is the paramount necessity of the people, people regard food as their prime want. The diet and the diet activity are the foundation of human survival and development. With the continuation and development of diet activities, it has formed a set of corresponding diet custom. Diet custom includes the types of diet, the way of diet, the taboo of diet and the custom and etiquette in the process of production, processing and consumption. Man and woman have obvious differences in the national diet etiquette in Xinjiang. But with the progress of the times, the unceasing enhancement of social civilization degree, the equality consciousness between man and woman is gradually awakened, the gender differences between man and woman are narrowed in the diet custom.

2. The attenuation of the gender differences between man and woman in diet activities

It inhabits a region of Uygur nationality, Kazak nationality, Hui nationality, and other family in Xinjiang. Affected by the social division of labor and religion, especially traditional man and woman difference, most of the national women undertake the task of the family food production, but it must be man first and woman second and man and woman can't sit at the same table at the time of consumption. At present, the roles of the fixed mode are changing.

\subsection{The attenuation of the gender differences} in the diet activity

1. The attenuation of the gender role differences in the food preparation stage. All nationalities in Xinjiang give priority to the pasta, they like to 
eat meat, such as the Hui Powder, the Uighur Nang and the roast mutton. Woman should finish the vessel preparation, choose and process the food raw materials separately in the traditional habits. Man also takes up some housework step by step in recent years. For example, it is a difficult and stronger technical work to do noodle in the Xinjiang Uygur nationality family, it is in need of a certain strength, man has more advantages than a woman. If we break the tradition that woman does it alone, it will not only reduce the burden of woman, but also accelerate the production process. We often see that it is taken up by man in the food business regardless of the Uighur nationality and Hui nationality. In fact, this kind of phenomenon also gradually develops in the family food production, the gender differences play down gradually in the diet activities.

2. The attenuation of the gender role differences in the food eating stage. The food preparation and production are done by only woman in the tradition. Man and woman are not equal in the process of diet, the custom is that man is the first, followed by the children, the last is housewife. In addition, some national minorities have the custom of man's and woman's different table. For example, there is the phenomenon that man and woman separately eat by dishes in the traditional family in the Uzbek nationality, woman can't go to the dinning, she must constantly put down her own food, make rice bowl and pour tea for the guests. In addition, Tajik nationality, Kirgiz nationality and Xibe nationality have the similar gender rules. The phenomena that man is the first and woman is the second and separate meals are gradually improved.

\subsection{The attenuation of the gender differences in the special occasion diet}

With the rising status of woman, woman also greatly increases the chance to attend all kinds of party, the gender differences also gradually narrow in the party diet custom. In some special occasions, such as the important festivals, the differences between man and woman are obvious in the Xinjiang minority nationality traditional diet custom. Such as most women make preparation to celebrate the Eid al-Adha and Id-al-Fitr holiday half a month ago in Islamic nationality. They not only buy the necessities in the market, but also do all kinds of food, even clean indoor and outdoor environmental sanitation. While man just takes the guest. The unequal differences between man and woman have also been gradually weakened in the diet custom of the Xinjiang minority nationality in real life. And woman not only often attends a variety of party, but also has some of the party, such as the Uighur nationality woman holds a tea party once a week, makes the leisure communication and man and woman can 
sit at the same table with meals.

\section{The cause of the attenuation of the gender differences in the diet activity}

As "half the sky", the social consciousness of woman is awakening, whether in the public places or family life woman gradually improves her own status. The gender differences are gradually weakening in the diet custom activities, the reason mainly has the following three points:

\subsection{The social potential requirements}

It has come a consensus that the family is composed of a couple in modern society. Woman goes into the social activities and the public domain business increasingly, man has to adapt to the era and consciously goes into the family the private sector. The traditional division of labor pattern in the family relationship transforms from the clear way to the fuzzy way, the society begins to try to a new view of man and woman relationships and the couple relationship. Most of the women have the freedom to choose the work, they can go outside the world that originally belongs to man's world, and man can also be involved in housework, take the common burden of the family, and have the negotiations on a major event such as the caring of the children and the old man. With the progress of social system, the custom that woman only takes up housework is changing in all nationalities of Xinjiang, they are no longer just a subservient to the man and only do household chores, they also walk to the society, and do something useful, while man also enters the domestic private sector and do some cooking or housework. Such as women do the specialty food of Sanzi and soup and carry on the exchange market in the Uygur nationality and Hui nationality, and men do some housework of shopping, washing the dishes and cooking at home. It is not a shameful thing, it is the necessity of social development.

\subsection{The awakening of female consciousness}

Consciousness is not only a product of nature, but also a product of society. The reflection of the consciousness to the physics and the society is active. People ideological change forms a huge impact on the original political relations and the values. The woman consciousness is awakening in the powerful impact of the current consciousness of equality of man and woman, and the identity is also changing. Woman is not a "nanny", not subservient to the husband, man can also take up housework, this is a new kind of family values, this is the result of social development. This inspires the woman independent ego consciousness and equality consciousness to a certain extent, breaks the original "balance" family patterns and narrows the gap between man and woman in the family. They go out to work, take up the business and handicraft industry, even set up factories. 
Whether the woman of Hui nationality, Uighur nationality or Xibe nationality, most of them obtain the economic income and realize the selfvalue, they also make contributions for the country, the society and the family. This is the result of times development and social progress, and it is also the result of the improvement of the woman social consciousness and their own autonomous consciousness.

\subsection{The influence of mass media}

The culture and language order is the foundation of all ruling order. The characteristics of the fast speed, wide coverage and high penetrability of the mass media determine it will subtly affect the general concept and behavior. Along with the gradual open social attitude toward the gender, people no longer mock the man who often shares the housework, they pay the tribute to them instead to a certain extent, and it has the close relationship with the mass media and the propaganda. The mass media propaganda makes a man feel proud to do housework and it is also one of the standard of a good man to let the society have the acceptance and do the household chores. Nowadays, the female and male common role is to do some housework, and have some social activities in many national family of Xinjiang,.

\section{The social significance of the attenuation of} the gender differences in the diet custom

\subsection{The traditional social gender consciousness suppresses woman's self- consciousness}

The value of woman is positioned in the family in the traditional society, women reflect their presence by housekeeping and raising children in the family. The "men outside the home, women inside" point of view binds the ideology of the realization of self-worth, but with the development of modern industrial civilization and the improvement of the social civilization degree, woman gradually moves towards the society to participate in the social labor, The differences between men outside the home, women inside have been improved, at the same time, it contributes to the attenuation of the differences between man and woman by the male participation in the family labor. At the same time, it can make the woman reduce the waste of time in the household chores, so she has time to improve her level of knowledge, skills and better realize self-worth.

\subsection{The pace of life is quickening and the competition is fierce increasingly in the modern world produce a series of social problems}

The pace of life is quickening and the competition is fierce increasingly in the modern world, and it produces a series of social 
problems. The family problems are the prominent problems. Man works under the pressure in the society and at the same time they also face all kinds of temptation, woman not only has more intense pressure of work in the society, but also bears the family burden, the contradiction between the two sides is once hit, it will be intensified. If man can try to participate in the daily life and lighten the woman burden of the family, it will make both tend to equal, it will help the family peace, and thus reduce the social pressure.

\subsection{It contributes to the improvement of woman's family status}

For a man, as long as the career succeeds, he is a winner. But it is not so simple for a woman, they have the special physiological requirements and bear the reproduction of human groups, and they are required to be both the family role model and the business role model, namely they are the winner only when they succeed in both the career and the family. Therefore, woman must fight for the equality of family roles to change the current situation that the society uses a double standard for the assessment of woman. The narrowing of the gender differences in the diet custom is a mapping of woman's family status improvement.

\section{Conclusion}

In a word, along with the progress of the times and the continuous improvement of social civilization, the consciousness equality between man and woman of all nationalities in Xinjiang is awakening, the gender difference is shrinking in the diet custom. The woman status is rising in the field of the public sector and the private family, and the diet activities are regarded as part of the family private sector, the gender differences are gradually narrowed. It is a reflection of the woman's status gradual improvement.

\section{References:}

[1] Wei Guoying. Introduction to woman[M]. Beijing: Beijing University Press, 2000

[2] [Shen Yifei. The construction of woman[M]. Shanghai: Shanghai People's Publishing House, 2005.

[3] $\mathrm{Su}$ Hong. The social gender theory under the multiple perspectives[M]. Shanghai: Shanghai University Publishing House, 2004.

[4] Yang Qichen, Yang Hua. Etiquette custom culture of the Chinese Muslim[M]. Yinchuan: Ningxia People's Publishing House, 1999.

[5] Ha Zhengli. Hui nationality diet taboo[J]. Journal of Hui Nationality Research, 2000, (4). 